\title{
A Sectored-One-Dimensional Model for Simulating Combustion Instabilities in Premix Combustors
}

\author{
Daniel E. Paxson
}

Glenn Research Center, Cleveland, Ohio 
Since its founding, NASA has been dedicated to the advancement of aeronautics and space science. The NASA Scientific and Technical Information (STI) Program Office plays a key part in helping NASA maintain this important role.

The NASA STI Program Office is operated by Langley Research Center, the Lead Center for NASA's scientific and technical information. The NASA STI Program Office provides access to the NASA STI Database, the largest collection of aeronautical and space science STI in the world. The Program Office is also NASA's institutional mechanism for disseminating the results of its research and development activities. These results are published by NASA in the NASA STI Report Series, which includes the following report types:

- TECHNICAL PUBLICATION. Reports of completed research or a major significant phase of research that present the results of NASA programs and include extensive data or theoretical analysis. Includes compilations of significant scientific and technical data and information deemed to be of continuing reference value. NASA's counterpart of peerreviewed formal professional papers but has less stringent limitations on manuscript length and extent of graphic presentations.

- TECHNICAL MEMORANDUM. Scientific and technical findings that are preliminary or of specialized interest, e.g., quick release reports, working papers, and bibliographies that contain minimal annotation. Does not contain extensive analysis.

- CONTRACTOR REPORT. Scientific and technical findings by NASA-sponsored contractors and grantees.
- CONFERENCE PUBLICATION. Collected papers from scientific and technical conferences, symposia, seminars, or other meetings sponsored or cosponsored by NASA.

- SPECIAL PUBLICATION. Scientific, technical, or historical information from NASA programs, projects, and missions, often concerned with subjects having substantial public interest.

- TECHNICAL TRANSLATION. Englishlanguage translations of foreign scientific and technical material pertinent to NASA's mission.

Specialized services that complement the STI Program Office's diverse offerings include creating custom thesauri, building customized data bases, organizing and publishing research results ... even providing videos.

For more information about the NASA STI Program Office, see the following:

- Access the NASA STI Program Home Page at http://www.sti.nasa.gov

- E-mail your question via the Internet to help@sti.nasa.gov

- Fax your question to the NASA Access Help Desk at (301) 621-0134

- Telephone the NASA Access Help Desk at (301) 621-0390

- Write to: NASA Access Help Desk NASA Center for AeroSpace Information 7121 Standard Drive Hanover, MD 21076 
NASA/TM-1999-209771

AIAA-2000-0313

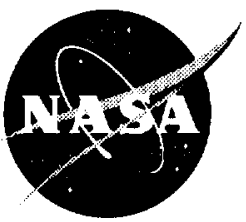

\section{A Sectored-One-Dimensional Model for Simulating Combustion Instabilities in Premix Combustors}

Daniel E. Paxson

Glenn Research Center, Cleveland, Ohio

Prepared for the

38th Aerospace Sciences Meeting and Exhibit

sponsored by the American Institute of Aeronautics and Astronautics

Reno, Nevada, January 10-13, 2000

National Aeronautics and

Space Administration

Glenn Research Center 
This report contains preliminary findings, subject to revision as analysis proceeds.

Trade names or manufacturers' names are used in this report for identification only. This usage does not constitute an official endorsement, either expressed or implied, by the National Aeronautics and Space Administration.

Available from

NASA Center for Aerospace Information

7121 Standard Drive

Hanover, MD 21076

Price Code: A03
National Technical Information Service 5285 Port Royal Road Springfield, VA 22100 Price Code: A03 
AIAA-2000-0313

\title{
A SECTORED-ONE-DIMENSIONAL MODEL FOR SIMULATING COMBUSTION INSTABILITIES IN PREMIX COMBUSTORS
}

\author{
Daniel E. Paxson ${ }^{\dagger}$ \\ National Aeronautics and Space Administration \\ Glenn Research Center \\ Cleveland, Ohio 44135, USA \\ Phone: (216) 433-8334 \\ Fax: (216) 433-8643 \\ Email: dpaxson@grc.nasa.gov
}

\begin{abstract}
A one-dimensional, CFD based combustor simulation has been developed that exhibits self-excited, thermoacoustic oscillations in premixed combustor geometries that typically have large, abrupt changes in cross sectional area. The combustor geometry is approximated by dividing it into a finite number of onedimensional sectors. Within each sector, the equations of motion are integrated numerically, along with a species transport and a reaction equation. Across the sectors, mass and energy are conserved, and momentum loss is prescribed using appropriately compatible boundary conditions that account for the area change. The resulting simulation and associated boundary conditions essentially represent a one-dimensional, multi-block technique. Details of the simulation code are presented herein. Results are then shown comparing experimentally observed and simulated operation of a particular combustor rig that exhibited different instabilities at different operating points. It will be shown that the simulation closely matched the rig data in oscillation amplitudes, frequencies, and operating points at which the instabilities occurred. Finally, advantages and limitations of the simulation technique are discussed.
\end{abstract}

\section{Introduction}

The problem of thermo-acoustic combustion instabilities in aircraft and land-based gas turbine engines is currently the focus of numerous research efforts ${ }^{1}$. Lean-premix, low emission combustor designs appear to be particularly susceptible to this phenomenon due to, among other things, their lack of cooling air and their acoustically stiff geometry. One possible solution to the instability problem is active or feedback control. Here, a signal from the system (e.g. pressure) is used to detect incipient instabilities, and some form of actuation (such as fuel flow perturbation) is used to suppress and restabilize the system. This is in contrast to present passive methods where the structure of the combustor is physically changed to avoid the instability entirely. Successful active control design however, is greatly enhanced by accurate modeling and simulation of the combustor of interest. The essential physical phenomena should be correctly captured. For example, the simulation should self-excite, as is often the case with the actual instability, as opposed to requiring some form of external forcing. On the other hand, dynamic characterization of the system required for control design necessitates parametric analyses and multiple simulation runs. This, in turn, places the practical requirement of high speed on the simulation.

For many combustor configurations, the underlying physics of the system are simply too complex to lend themselves to any sort of simplified approach that is practical for active control design. Instabilities that are both longitudinal and circumferential for instance, or those that are intricately tied to some vortex shedding phenomenon are examples.

If however, the instabilities are predominantly oriented along one spatial dimension, and if consideration is limited to premix type combustion, then it may be possible to satisfy the simulation objectives of numerical speed (i.e. model simplicity), and physical accuracy. Such restrictions, though severe, apply to a large number of combustors. This paper introduces a

\footnotetext{
Senior Member, AIAA

Copyright (c) 2000 by the American Institute of Aeronautics and Astronautics, Inc. No copyright is asserted in the United States under Title 17, U.S. Code. The U. S. Government has a royalty-free license to exercise all rights under the copyright claimed herein for Govemmental Purposes. All other rights are reserved by the copyright owner.
} 


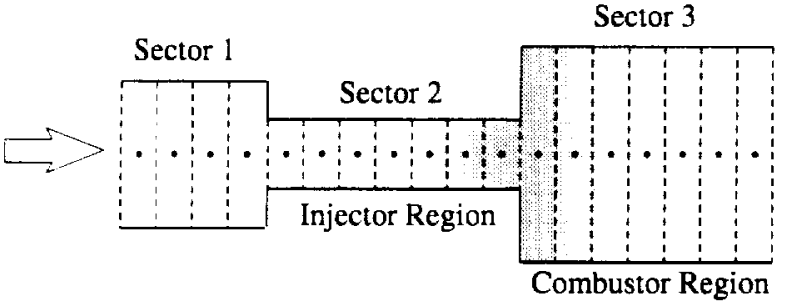

Figure 1.-Lean premix combustor schematic.

method to achieve the simulation goals just described with the added, essential, capability of accounting for the large and abrupt changes in cross sectional area typically associated with premix combustors. An example of such geometry is shown schematically in Fig. 1.

The combustor geometry is approximated by dividing it into a finite number of one-dimensional (constant area) sectors. Within each sector, the equations of motion are integrated numerically, along with a species transport and a very simple one-step reaction equation. This aspect of the simulation has been used successfully to investigate both deflagrative and detonative combustion processes for a variety of applications ${ }^{2-4}$. Across the sectors, mass and energy are conserved, and momentum loss is prescribed using appropriately compatible boundary conditions that account for the area change. This approach avoids the difficulties often found when quasi-one-dimensional computational schemes are applied to geometries with abrupt area changes".

Details of the simulation methodology are presented herein. These include a presentation of the assumed governing equation set, a description of the numerical integration scheme, and an algorithmic description of the boundary conditions that tie two sectors together. A simple, non-reactive acoustic flowfield simulation is then shown which serves (somewhat heuristically) to validate the sectored approach. A Pulse Jet simulation is then presented which clearly demonstrates the capability of capturing thermo-acoustic oscillations in a device that exhibits them by design. Comparisons are then made between experimentally observed and simulated instabilities in a specific combustor rig. The rig was a critical test of the approach in that it had multiple, abrupt area changes and it exhibited two different unstable limit cycles at two different operating points. It will be shown that the simulation successfully exhibited the self-excited oscillations at the correct frequencies, amplitudes, and operating points. The paper concludes with a discussion of the possible advantages and limitations of the simulation technique.

\section{Governing Equations}

Given a combustor geometry which has been suitably divided into one-dimensional sectors, within each sector the numerical integration is performed on the following governing differential equations for a calorically perfect gas, written below in non-dimensional form

$$
\frac{\partial \bar{w}}{\partial \mathrm{t}}+\frac{\partial \overline{\mathrm{F}}(\overline{\mathrm{w}})}{\partial \mathrm{x}}=\overline{\mathrm{S}}(\overline{\mathrm{w}}, \mathrm{x})
$$

where

$$
\overline{\mathrm{w}}=\left[\begin{array}{c}
\rho \\
\frac{\rho \mathrm{p}}{\gamma(\gamma-1)}+\frac{\rho \mathrm{u}^{2}}{2}
\end{array}\right]
$$

and

$$
\bar{F}=\left[\begin{array}{c}
\rho u \\
\frac{p}{\gamma}+\rho u^{2} \\
u\left(\frac{p}{\gamma-1}+\frac{\rho u^{2}}{2}\right) \\
\rho u z
\end{array}\right]
$$

The distance, $x$ has been normalized by the combustor length, $L$. The time, $t$ has been normalized by the characteristic wave transit time, $L a^{*}$, where $a^{*}$ is the speed of sound at a chosen reference state. The pressure, $p$ and density, $\rho$ have been normalized by their respective reference values and the axial velocity, $u$ has been normalized by $a^{*}$. The mass fraction of reactant is $z$. Note that $z$ can be related to, but is not the same as, actual fuel fraction. The ratio of specific heats is denoted by $\gamma$.

For this non-dimensionalized form of the equations, the equation of state is written

$$
p=\rho T
$$

The speed of sound is simply $\sqrt{ } T$.

\footnotetext{
- These are discussed briefly in the appendix of this paper. As of this printing, the author has not found a q-1-d approach that successfully simulates the particular combustor presented herein.
} 
The non-dimensional source vector is written as:

$$
\bar{S}(\bar{w}, x)=\left[\begin{array}{c}
\frac{\partial}{\partial x}\left(\frac{\varepsilon_{1}}{\operatorname{Re}^{*}}\left(\frac{\partial u}{\partial x}\right)\right)+\sigma_{2} u|\rho u|^{0.75} \\
\frac{\partial}{\partial x}\left(\frac{\varepsilon_{t}}{\operatorname{Re}^{*}} \frac{\partial}{\partial x}\left(\frac{u^{2}}{2}+\frac{T}{(\gamma-1) \operatorname{Pr}_{t}}\right)\right) \\
+\frac{T^{0} \dot{m}_{s}}{\gamma-1}+q_{0} R+Q_{b t} \\
\dot{m}_{r}+\frac{\partial}{\partial x}\left(\frac{\varepsilon_{1}}{\operatorname{Re}^{*} S c_{t}}\left(\frac{\partial z}{\partial x}\right)\right)-R+\dot{\mathrm{m}}_{s} z_{s}
\end{array}\right]
$$

It may contain contributions from reaction, turbulent eddy diffusion, wall viscous forces, heat transfer, and supplementary flows (including reactant flow such as a fuel injector). The Reynolds number, $R e^{*}$ is defined as $\rho^{*} a^{*} L / \mu$. The turbulent viscosity ratio, $\varepsilon_{q}$ is defined as the ratio of turbulent to molecular viscosity, $\mu_{\mathrm{r}} / \mu$. The heat of reaction is $q_{0}$, which has been normalized by the square of the reference speed of sound. $R$ is the reaction rate, defined below. $P r_{t}$ and $S c_{t}$ are the turbulent Prandtl and Schmidt numbers respectively. It is noted that the ratio $\mu_{t}$ $/ \mu$, as well as $P r_{t}$ and $S c_{t}$, are not necessarily physically based. They are chosen to represent 'effective' diffusion coefficients which allow the diffusion terms of the governing equations to mimic the transport behavior of, say, large recirculation zones and/or shear layers. For the results presented in this paper, the value of the wall friction coefficient, $\sigma_{2}$ is zero.

\section{Combustion Model and Reaction Rate}

The reaction rate of the modeled combustion process is a very simple, single species equation of the form:

$$
R=K_{0} \rho z\left(\zeta_{1}-\zeta_{2} z\right)\left\{\begin{array}{cl}
1-\left(T_{i g n} / T_{i}\right) & ; T_{i}>T_{i g n} \\
0 & ; T_{i}<T_{i g n}
\end{array}\right\}(6)
$$

where $K_{0}$ is the reaction rate constant (normalized by the reference wave transit time), $\zeta_{1}$ and $\zeta_{2}$ are constants defining the type of reaction, $T_{i g n}$ is the ignition temperature and $T_{i}$ is the temperature in the $i^{\text {th }}$ numerical cell. This reaction model has been used with success for, among others, the numerical simulation of propulsion devices with non-steady burning ${ }^{2}$. For the results presented herein, the value of $\zeta_{2}$ was set to 0.0 .

\section{Flameholding}

A model for flameholding is not shown per se in the governing equations. It is modeled as a distribution in the value of the turbulent diffusion coefficient, $\varepsilon_{t}$. In particular, the value in the simulation results to be presented changes from zero to some maximum prescribed value over $5 \%$ of the combustor length. It is then gradually reduced to zero over the distance between the location of the maximum value and the end of the sector. The location of this transition must also be prescribed. Typically, it begins in the vicinity of a known dominant recirculation zone. Obviously, this is an extremely crude model for flameholding and currently requires a degree of 'tuning' to avoid such phenomena as blow-out. Furthermore, the particular form and location of the diffusion coefficient distribution has been found to strongly influence the formation of self-excited oscillations. On the other hand, the notion of using a diffusion equation to model recirculation and mixing is a natural one that, with additional analysis, may be possible to generalize and quantify.

\section{Heat Transfer}

The term $Q_{\mathrm{ht}}$ in Eqn. 5 is represented by a simple algebraic expression

$$
Q_{b 1}=\alpha\left(T_{i n f}-T_{i}\right)
$$

where $\alpha$ is a user specified constant (and may depend on the velocity and density if convective), $T_{\text {inf }}$ represent an assumed temperature of the surface or space to or from which heat may be transferred, and $T_{i}$ is the (computed) gas temperature in the $i^{\text {th }}$ cell. In the combustor simulation results to be presented, this term is used to model the effects of cooling spray in the downstream portion of an experimental rig. The value of $\alpha$, and the combustor extent over which the term acts was determined by matching simulation results with experimental measurements.

\section{Numerical Method}

The simulation numerically integrates the above equations of motion using a very simple, second-order MacCormack scheme ${ }^{5}$. A Baldwin-MacCormack type artificial viscosity scheme has been added in order to damp non-physical oscillations in vicinities of strong spatial gradients such as those brought about by the combustion process. Typically, this type of artificial viscosity uses a spatial pressure profile as a weighting coefficient. In this simulation a density profile is used instead for the mass, momentum, and energy equations, and a reaction fraction profile is used in the species transport equation. The numerical scheme and associated artificial viscosity were chosen because of the computational speed which they afford. 
Boundary Conditions

Boundary conditions are the means by which area changes are accounted for, and by which numerical image cell states are prescribed. In hyperbolic systems they allow computation of interior cell states. Boundary conditions at each sector may be imposed as either partially opened, fully open, choked inflow (i.e. constant mass flux), or solid walls. In any case the code anticipates the flow direction and applies appropriate (i.e. well-posed) states to image cells just outside the computing domain. These are described briefly below. Details may be found in Refs. 6 and 7 .

\section{Fully Open}

If the flow is outward from the computing domain, only the static pressure is imposed. The remaining information (density, velocity, and reaction fraction) is obtained via characteristic jumps across the adjacent numerical cell. If the flow is inward, total pressure and temperature, and reaction fraction are imposed. The remaining unknown quantity (velocity) is obtained through iteration and characteristic jumps across the adjacent numerical cell. In this case the image cell state ultimately meets the simultaneous requirements of having the imposed total pressure and temperature, and having no outward-running characteristics.

\section{Partially Open}

This type boundary is depicted in Fig. 2. Depending upon the external conditions, the flow will be either in or out of the computing domain. Looking first at the inflow scenario (a), the external flow is modeled as isentropic and steady relative to some prescribed stagnation state (as in the fully-open case above). Adjacent to this region is an imaginary "mixing region" where the fluid changes from a highly non-uniform distribution across the partially open tube on the left to some mixed out average on the right. The mixing is modeled as instantaneous, and the extent of the mixing region is modeled as infinitesimal. Adjacent to this region is the first "cell" of the computing domain for which, at the present time, the conditions are completely known. The two zones are related by the following mass momentum and energy equations:

$$
\begin{aligned}
& \rho_{0} u_{0}=\rho_{e} u_{e} \frac{A_{e}}{A_{t}} \\
& P_{0}=P_{e}-\gamma \frac{\rho_{e} u_{e}{ }^{2}}{2}\left(1-\frac{A_{e}}{A_{l}}\right)^{6} \\
& \left(\frac{\gamma}{\gamma-1}\right) u_{0} p_{0}+\frac{1}{2} \rho_{0} u_{0}{ }^{3}=\rho_{e} u_{e} H \frac{A_{e}}{A_{l}}
\end{aligned}
$$

Here, $\mathrm{H}$ is the total enthalpy. The subscripts 0 and $e$ in these equations designate the end and the beginning

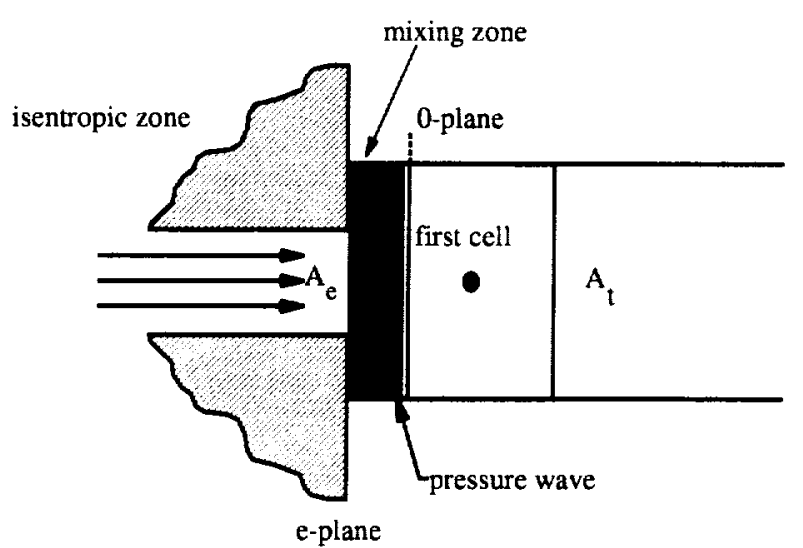

(a)

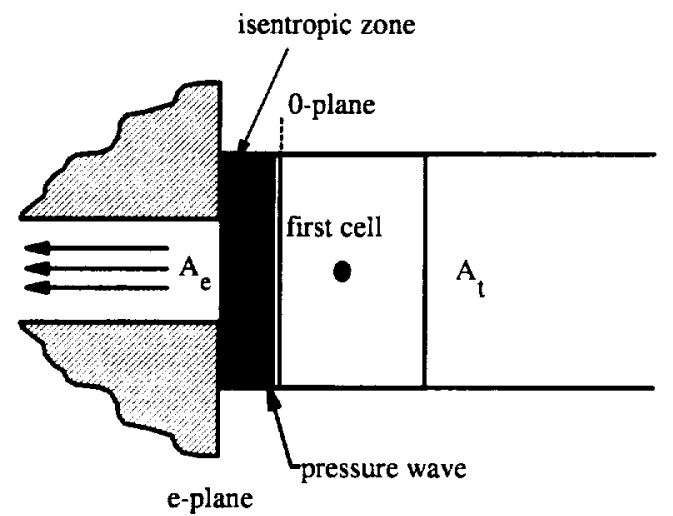

(b)

Figure 2.-Partially open boundary condition schematic; (a) Inflow, (b) Outflow.

planes of the mixing zone respectively, as shown in Fig. 2. If the pressure at the exit of the isentropic region, $\mathrm{p}_{c}$ is specified then, given the known stagnation there and the area ratio of the exit to the tube, $\frac{A_{c}}{A_{t}}$ the conditions at the exit plane are completely known. Equations 8-10 may then be used to find $\rho_{0}, p_{0}$, and $u_{0}$.

The conditions $p_{1}, \rho_{1}$, and $u_{1}$ in the first computational cell of the tube are also known. The difference between $p_{0}$ and $p_{1}$ will give rise to either a compression or expansion wave travelling to the right. The pressure ratio across the wave and the conditions in the first cell are sufficient information to analytically determine the velocity behind it, $\mathrm{u}_{0}{ }^{*}$ using Riemann invariants ${ }^{8}$. Since nothing has been said regarding the choice of $p_{e}$, it is not expected that $u_{0}{ }^{*}$ will be the same as $u_{0}$ calculated using equations 8-10. A function may be defined however, as

$$
\mathrm{y}\left(\mathrm{p}_{\mathrm{e}}\right)=\mathrm{u}_{0}-\mathrm{u}_{0}^{*}
$$


The proper choice of $\mathrm{p}_{\mathrm{e}}$ is that for which $\mathrm{y}$ is identically zero. This cannot be found analytically but may be obtained using a convenient numerical root finding technique (e.g. the false point method ${ }^{9}$ ). The values of $p_{0}, \rho_{0}$, and $u_{0}$ obtained through the solution of equation 11 are then assigned to the left image cell of the computing space.

For outflow, consider Fig. 2(b). Here, the external region is modeled using a constant, known static pressure, $p_{c}$. Adjacent to this is a fictitious zone in which the flow is isentropic and which, like the mixing zone above, adjusts instantaneously to flow conditions. Again, conditions in the first cell of the computing space are known. Under these modeling assumptions, for any value of $p_{0}$ chosen a value of $u_{0}$ may be found to satisfy characteristic relations between the first cell and the image cell. Similarly, a value of $u_{0}{ }^{*}$ may be found to satisfy steady isentropic relations between the exit plane and the image cell. Through iteration, in a manner similar to the inflow scenario, a value of $p_{0}$ may ultimately be obtained for which $\mathrm{u}_{0}$ and $\mathrm{u}_{0}{ }^{*}$ are identical. Detailed descriptions of similar boundary conditions may be found in Ref. 7 .

\section{Choked Flow}

In this type of boundary condition, the quantity $\rho_{0} u_{0}$ is specified along with the external stagnation temperature $\mathrm{T}_{0}$. The unknown quantities $\mathrm{p}_{0}$ and $\mathrm{u}_{0}$ required for the image cell are found through Riemann invariants and iteration.

\section{Wall}

For this boundary condition the quantities $p_{0}, \rho_{0}$, and $u_{0}$ are simply assigned the values $p_{1}, \rho_{1}$, and $-u_{1}$ respectively.
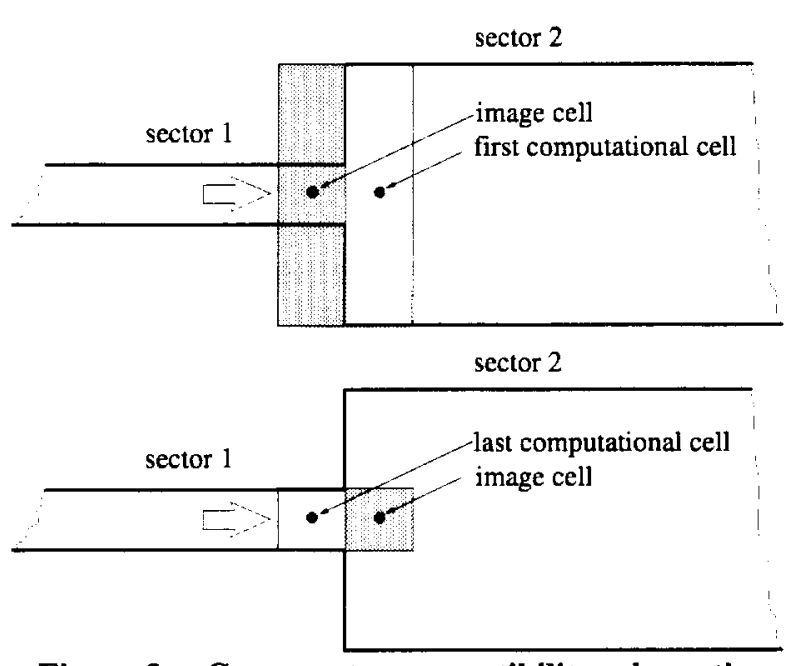

Figure 3.-Cross-sector compatibility schematic.

\section{Crossing Sectors/Area Change}

Compatibility between sectors is ensured by combining a fully-open type boundary condition for one sector and a partially-open boundary condition of another. For example, consider the geometry shown in Fig. 3 where the flow is from left to right. A guess is made for the exit pressure of sector 1 . The state of the fully-open image cell for this sector is used to calculate stagnation properties. These, in turn, are used to determine the image cell state for the partially-open configuration of sector 2. The area of each sector is known. Thus, for the assumed exit pressure of sector 1, the mass flux ( $\rho u A)$ in the image cell of each sector is also known. The proper choice of sector-1 exit pressure then is that which yields the same mass flux in both sectors. This must be found through iteration.

If the geometry is and flow conditions are such that flow is from a large to a small area sector, a similar iteration can be established using the fully-open inflow and partially-open outflow boundary conditions described above.

At present, the area change aspect of the simulation is limited to unchoked flow; however, the method just described can easily be modified to accommodate choked flow with abrupt area change.

\section{Acoustic Validation}

As a check on the validity of the sectored-onedimensional approach just described, a non-reactive, purely Euler calculation (i.e. the source vector identically zero) was performed on a tube with the geometry shown as the dashed line in Fig. 4. This geometry approximates the cross sectional area of a

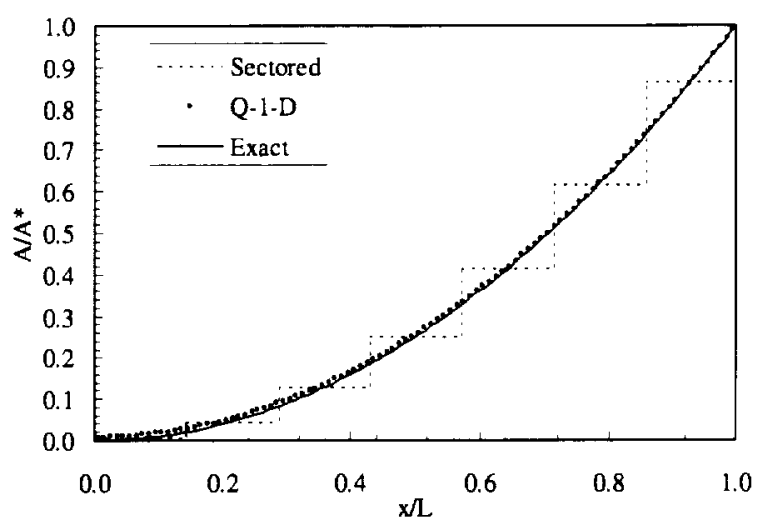

Figure 4.-Sectored and Q-1-D approximations to the area profile of a conical section. 
conical section shown as a solid line. Also shown in the figure, as a dotted line, is the profile that was used for a quasi-one-dimensional (Q-1-D) calculation. Details of the Q-1-D formulation are not presented here. The calculation results are included for comparative purposes. The fundamental non-dimensional frequency for this shape $\left(f^{\prime}=\frac{f L}{a^{*}}\right)$ is known to be $f^{\prime}=0.5$ with harmonics of $1.0,1.5$, etc ${ }^{9}$. Note that this is in contrast to a tube of uniform cross section and closed at one end, where the fundamental and harmonic frequencies are $0.25,0.75,1.25$, etc. If the conical tube simulations are excited by a pressure impulse at the open ends from a state of uniform pressure, temperature and zero velocity, the responses should contain the fundamental mode and several harmonics. The results of just such an excitation are shown in the Power Spectrum of Fig. 5. The computations were done with 100 numerical cells. The non-dimensional duration of both Q-1-D and Sectored simulations was 50 time units. The time interval for the data used in power spectrum analysis was 0.1 time units. The excitation was a pressure spike at the open end $10 \%$ above ambient pressure, lasting 0.5 time units. Pressure from the first interior cell, measured from the left end, was used to make the spectrum. The computed results are very similar for the two methods. Both Q-1-D and Sectored spectra are correctly dominated by the modes corresponding to the conical profile that was being simulated. While this not conclusive validation of the method just presented, it does provide confidence in the results that follow.

\section{Pulse Jet Validation}

As a second validation demonstration of the simulation method a Pulse Jet was considered. These propulsion devices, which capitalize on the coupling between

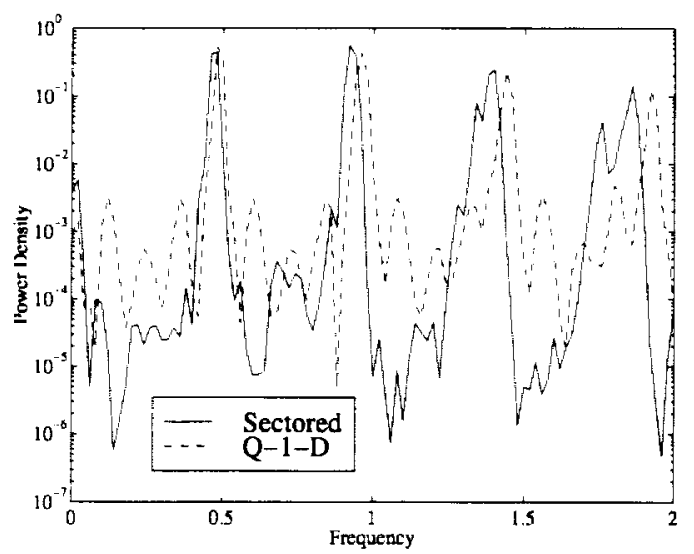

Figure 5.-Computed sectored and Q-1-D power spectral densities of pressure in the first cell of an approximated conical area profile using a single 0.5 time unit exit pressure spike excitation. pressure fluctuation and heat-release, have been around for some time. They are generally very inefficient but also very simple in that they have no moving parts whatsoever. Commercial devices have been constructed. One such device, built by the SNECMA Company of France, has been documented in the literature ${ }^{11}$. The geometry is critical to performance; however, it should be possible to obtain large sustained oscillations with a geometry that is similar to a pulse combustor (these devices typically operate with pressure oscillations well above normal acoustic levels). Such a simplified geometrical layout, appropriate for the S-1-D code is shown in Fig. 6. Numbers along the top of this figure represent cross sectional areas scaled by the combustion section. The numbers along the bottom represent fractions of the total length.

This simulation was run until limit cycle behavior was achieved. Limit cycle behavior is defined here as a repeating cycle with no change in peak-to-peak amplitude. The resulting wave pattern shown in Fig. 7 . The figure shows contour shades of non-dimensional pressure temperature, Mach Number, and rate of heat release. Reference conditions for the nondimensionalization correspond to Sea-Level-Standard. The horizontal direction corresponds to distance along the pulse jet. The vertical direction corresponds to nondimensional time. Numbers to the left of each contour represent the maximum and minimum value found in the $x-t$ space. It is noted that the simulation had run for at least one 200 time units before this figure was made. In this figure, the total time is 5.0 non-dimensional units. It is clear that strong, self-sustained oscillations are present as expected. Peak-to-peak pressure oscillations of $52 \%$ of the mean value were computed in the combustion chamber. The frequency of oscillations corresponds to that reported in the literature. The simulation was made with 200 cells. The mean fuel/air ratio for these devices is unknown; however, they are designed to run under standard atmospheric inlet conditions. It was assumed that the peak temperature allowed is $2300 \mathrm{R}$. The reactant source term, $\dot{\mathrm{m}}_{\mathrm{r}}$ in the source vector (Eqn. 5) was applied to a single numerical cell at the location shown in Fig. 6 and was adjusted to achieve this value.

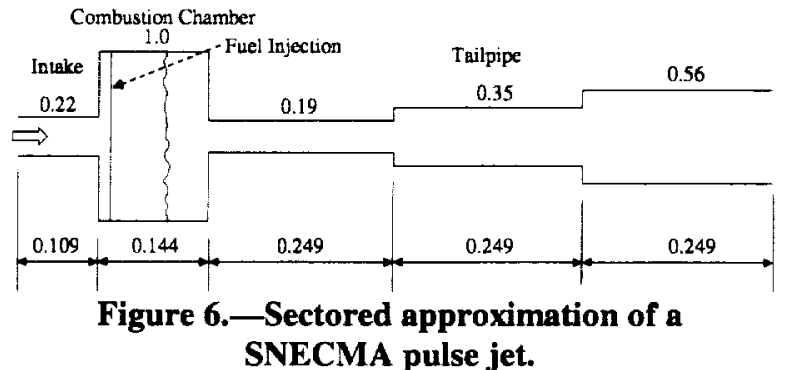



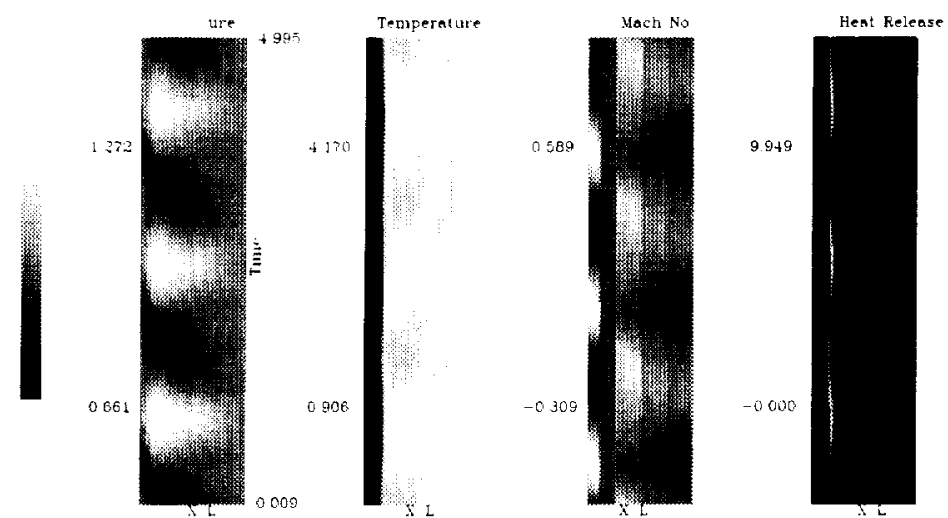

Figure 7.-Contours of non-dimensional pressure, temperature,

Mach number, and heat release rate during several cycles of a SNECMA pulse jet simulation.

As expected, this and subsequent simulation results to be presented satisfied Rayleigh's Criteria ${ }^{12}$ for instability. Figure 8 shows the integral

$$
\mathrm{Ra}=\mathrm{q}_{0} \int_{0}^{1} \mathrm{R}^{\prime} \mathrm{p}^{\prime} \mathrm{dx}
$$

for the Pulse Jet simulation over the approximately three cycle time period illustrated in Fig. 7. The primes in Eqn. 12 refer to fluctuations from the time-mean value of reaction rate and pressure. Rayleigh's Criteria, which is essentially a measure of the phase relationship between heat-release and pressure fluctuation, requires that the integral of $\mathrm{Ra}$ over one oscillation be positive, which it clearly is.

It is interesting to note in passing that Pulse Jets are decidedly non-premix devices, yet were successfully simulated here. This may suggest utility of the method just presented beyond the original premix restriction.

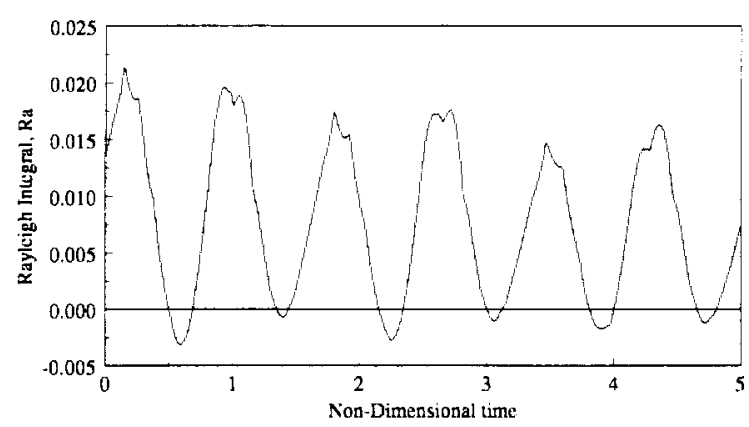

Figure 8.-Computed Rayleigh Index for the SNECMA pulse jet simulation.

\section{Combustor Simulation Results}

In a further effort to demonstrate the capabilities afforded by the method described above, a simulation of an experimental combustion rig exhibiting known instabilities was implemented. The instabilities exhibited by the rig were associated with sections beyond the expected injector and combustion zone. As such it was necessary to include the downstream plenum and cooling ring in the computing domain. The geometry simulated is shown in Fig. 9. For the results to be shown, 348 numerical cells were used.

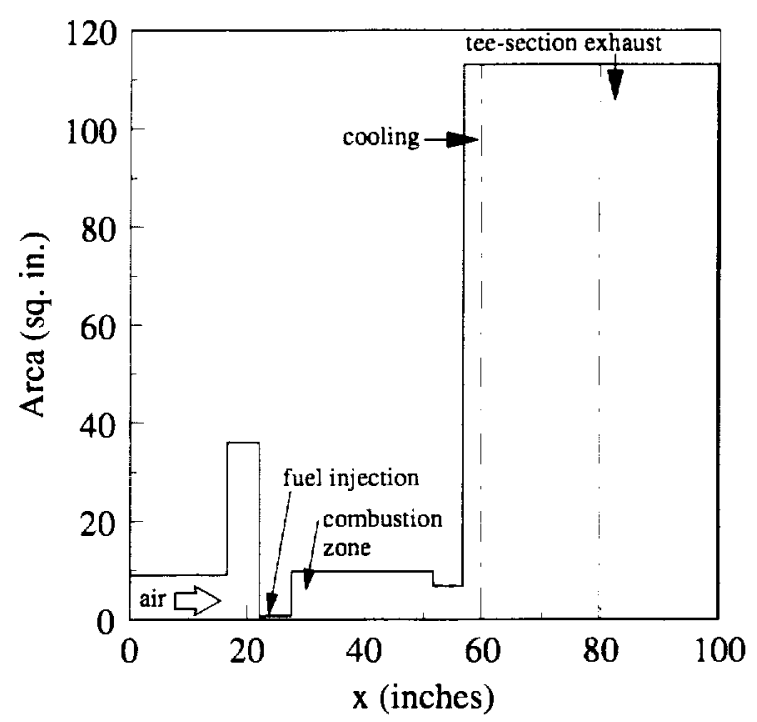

Figure 9.-Combustion rig geometry. 
The left side boundary conditions $(x=0.0$ in.) were modeled as fully-open, constant pressure. The right side boundary conditions ( $x=99.6 \mathrm{in}$.) were those for a solid wall. Flow exited the rig through a tee-section pipe 17 in. from the right end. This was modeled in the simulation using an orifice type equation representing $\dot{m}_{s}$ in the source vector, distributed over a number of computational cells. Flow through each orifice is driven by the ratio of pressure in the numerical cell to that of an imposed back pressure.

The cooling spray was modeled using the simple conductive Eqn. 7 applied to all computational cells in the domain beyond (to the right of $x=59.62 \mathrm{in}$. The value used for $T_{\text {inf }}$ in this equation was the measured exhaust temperature of approximately $760 \mathrm{R}$. The value of $\alpha$ was adjusted until the gas temperature at the beginning of the tee-section was equal to the measured exhaust temperature. This type of simplistic model implies that the dominant effect of the cooling spray is the changing of the gas temperature (e.g. speed of sound). This may not always be the case; however, the model seems to be effective for the rig results presented here.

Like the Pulse Jet simulation, fuel injection was modeled with the $\dot{\mathrm{m}}_{\mathrm{r}}$ term of the source vector applied to a single numerical cell at the location shown in Fig. 9. The source term was held at a constant value for each operating point to be described. This implies a constant fuel flow rate, which is appropriate due to the large fuel supply pressure of the rig.

Two operating points were simulated that exhibited two distinct frequency instabilities. The conditions for the operating points are listed in Table 1 . The subscript 3 in this table represents an upstream location near the inlet. The subscript 4 represents a downstream location near $\mathrm{x}=40.0 \mathrm{in}$. It is noted that conditions at Operating Point 2 also represent the reference conditions used for nondimensionalization. Thus, any non-dimensional results presented may be dimensionalized using these values.

Other relevant parameters of the simulations are listed in Table 2. The first three values in this table were chosen, adhoc, because they produced instability in the simulation. The turbulent Schmidt and Prandtl numbers, and the

Table 1.-Combustor operating points.

\begin{tabular}{|c|c|c|c|c|c|c|}
\hline Pnt. & $\begin{array}{c}\mathrm{P}_{3} \\
\text { Psia }\end{array}$ & $\begin{array}{c}\mathrm{T}_{3} \\
\mathrm{R}\end{array}$ & $\begin{array}{c}\dot{\mathrm{m}} \\
\mathrm{lbm} / \mathrm{s}\end{array}$ & $\gamma$ & $\mathrm{A} / \mathrm{F}$ & $\begin{array}{c}\mathrm{T}_{4} \\
\mathrm{R}\end{array}$ \\
\hline 1 & 155 & 1101 & 0.665 & 1.35 & 0.038 & 3307 \\
\hline 2 & 244 & 1361 & 1.34 & 1.35 & 0.024 & 2858 \\
\hline
\end{tabular}

Table 2.-Combustor simulation parameters.

\begin{tabular}{|l|l|}
\hline$\varepsilon_{\sqrt{ }} / \mathrm{Re}^{*}$ & 0.00056 \\
\hline $\mathrm{K}_{0}$ & 26.0 \\
\hline flame & 27.6 in. \\
\hline $\mathrm{Sc}_{\mathrm{L}}$ & 1.0 \\
\hline $\mathrm{Pr}_{1}$ & 1.0 \\
\hline $\mathrm{T}_{\mathrm{i}}$ & 1.25 \\
\hline $\mathrm{g}_{0}$ & 7.0 \\
\hline $\mathrm{p}_{\text {back }}$ & 54932 \\
\hline$\Delta \mathrm{t}$ & .00133 \\
\hline
\end{tabular}

ignition temperature were chosen based on engineering estimates. The value of $q_{0}$ was somewhat arbitrary. The value used, in conjunction with $\dot{\mathrm{m}}_{\mathrm{r}}$, determines the available chemical energy. The time step, $\Delta t$, was chosen based on numerical stability considerations.

The simulated position of the flame (reaction front) is determined by a prescribed distribution of the various diffusion coefficients (species, temperature, and momentum) as described earlier. The existence of an unstable operating point is often quite sensitive to the flame position both in terms of its proximity to the injection point, and in terms of its overall location in the combustor. As such, if an instability is observed, moving the flame position slightly restores steady-state operation. This technique was used in the simulation to achieve initially stable operation at the conditions listed in Table 1.

For reference, stable distributions of temperature and Mach Number for Operating Point 1 are shown in Fig. 10. Pressure and non-dimensional reaction rate ( $R$ in Eqn. 6) are shown in Fig. 11. The slightly wavey appearance of the Mach Number and pressure at the left side of the figures is due to the deliberate introduction of small random pressure oscillations at the inlet. These had a maximum value of $\pm 0.5 \%$ of the mean. They were intended to simulate noise from unknown sources in the system.

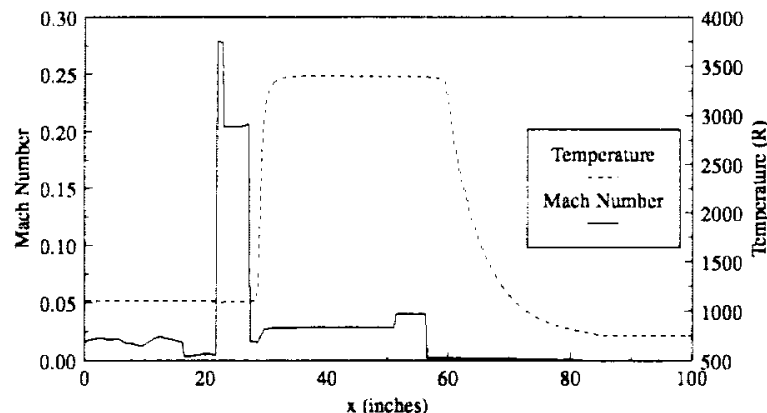

Figure 10.-Steady-state distributions of temperature, and Mach number at operating point 1 . 


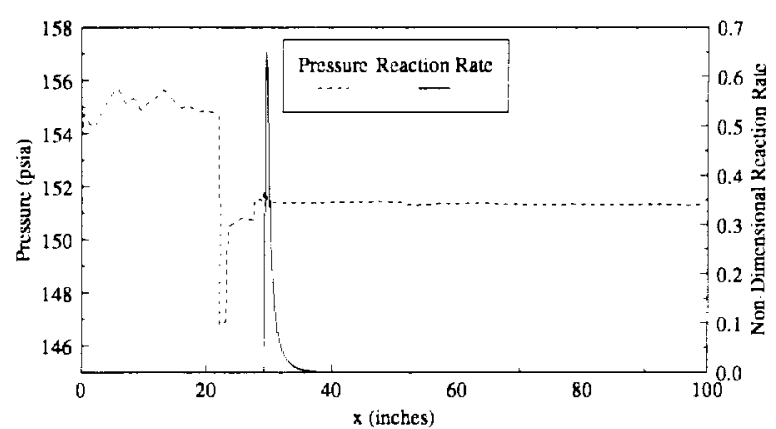

Figure 11.-Steady-state distributions of pressure, and non-dimensional reaction rate at operating point 1.

It should be noted that the rig geometry of the two operating points was slightly different. For Operating Point 1 , the narrow region where the fuel is injected was 1.0 in. shorter than is shown in Fig. 9. The large cross section sector preceding this was $1.0 \mathrm{in}$. longer than is shown. Thus the overall length was the same. For Operating Point 2, the geometry was as shown in Fig. 9. These slight differences were included in each simulation.

\section{Operating Point 1}

With the flame position properly placed, self-excited, unstable operation commenced, and eventually reached limit cycle behavior. Limit cycle behavior is defined here as a repeating cycle that exists after at least 4 seconds of simulated time with no significant change in peak-to-peak amplitude. The computed peak-to-peak amplitude of the pressure fluctuations at $x=42.1$ in. (the location of a pressure transducer) was approximately $7.7 \%$ of the mean. This is close to the $8 \%$ value measured experimentally. Contour plots of nondimensional pressure and velocity fluctuations (deviations from the time-mean values) are presented in Fig. 12 for approximately 2 oscillatory cycles. These are presented in order to show the mode shape of the instability. It would appear that this limit cycle is primarily the quarter wave mode of the combustor section proper; however, other modes are present.

Measured and computed Power Spectral Density distributions (PSD) of pressure at the experimental transducer location of $x=42.1$ in. are presented in Fig. 13. The signal used for the computed results was of 0.116 seconds duration at a $10 \mathrm{khz}$. sampling rate. For the measured results the signal duration was at least 10 seconds at the same $10 \mathrm{khz}$. sampling rate. The match between measured and computed power spectra is, in many ways, remarkable. The critical similarities, of course, are the frequency and power density associated with the instability. For reference, the measured dominant frequency was $275 \mathrm{hz}$. The
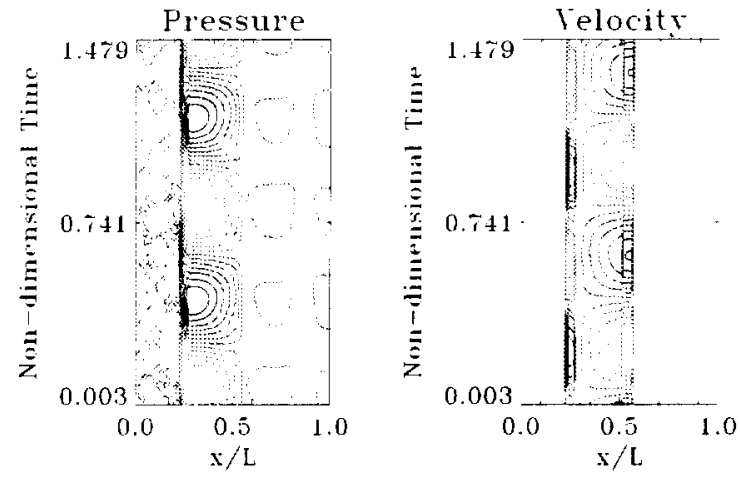

Figure 12.-Contours off non-dimensional pressure and velocity fluctuations for 2 cycles of the operating point 1 limit cycle.

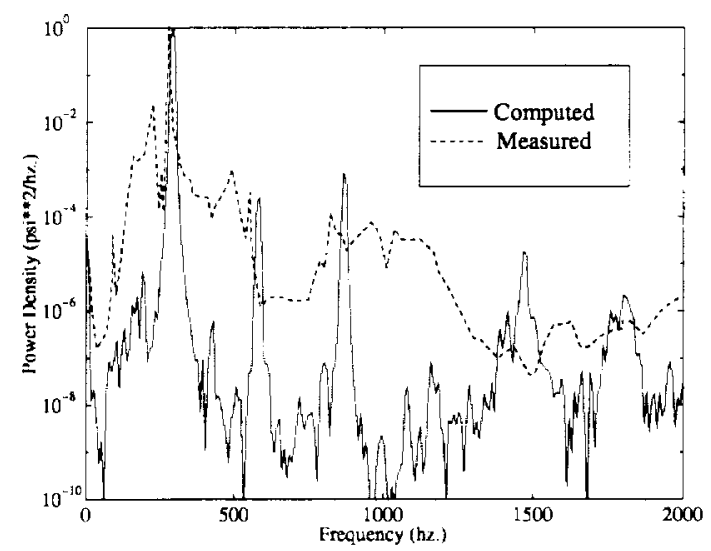

Figure 13.-Power spectral density distribution of pressure for $x=42.1$ inches during the operating point 1 limit cycle.

computed value was $291 \mathrm{hz}$. Although differing significantly in magnitude, the presence of higher frequency modes can be seen at approximately 570 and $850 \mathrm{hz}$. in both the computed and measured spectra. This suggests that the subtle acoustic properties of the rig are reasonably reproduced in the simulation. It is interesting to note that the $850 \mathrm{hz}$. signal corresponds to the $3 / 4$ wave mode of the combustor section proper. The $550 \mathrm{hz}$. peak however seems to be unrelated. Another striking similarity between measured and computed power spectra is the visible low frequency peak of approximately $188 \mathrm{hz}$. What makes this striking is that first, it is the dominant mode found at Operating Point 2 and second, that it is not a subharmonic of the $275 \mathrm{hz}$. mode.

Beyond $1000 \mathrm{hz}$. , there are large disparities between measured and computed power spectra. The reasons for this are unclear. One possible explanation is that there are other acoustic sources in the vicinity of the 
experimental pressure transducer such as a cooling water spray bar, and vorticies shed from recirculation zones that are not modeled in the simulation.

\section{Operating Point 2}

As with Operating Point 1 , the simulation successfully reproduced the observed instability at approximately the correct frequency and amplitude. The measured peakto-peak pressure oscillations were $3.6 \%$ of the mean. The computed oscillations were $3.1 \%$ of the mean. The measured dominant frequency was $175 \mathrm{hz}$. while the computed value was $188 \mathrm{hz}$. Figure 14 shows the same type contour plot as Fig. 12 in order to illustrate the dominant oscillatory mode. It is clear that this mode is completely different in form from that of Fig. 12 and that the downstream plenum of the rig is acoustically active. This mode is the main reason that it was necessary to simulate such a large portion of the rig.

The measured and computed power spectra for this operating point are shown in Fig. 15. As before, the computed and measured results agree well with respect to amplitude and frequency of the dominant instability. The qualitative agreement is also quite good in some respects. In particular, both show the dominant low frequency mode, and the virtual absence of the $275 \mathrm{hz}$. mode found at Operating Point 1 . Both also show a second peak near $380 \mathrm{hz}$. The source of this is unknown. The measured results show a peak at $450 \mathrm{hz}$. which is not seen in the computed results. The explanation for this is unclear at the present time.

\section{Discussion}

The results of the simulation just presented are encouraging in as much as they successfully duplicated self-excited instabilities observed in a rig with relatively complex geometry. It is also encouraging that a simulation of this combustor rig lasting 0.116 seconds of computed time took 188 seconds of CPU time running on a Sun Ultra 2 Workstation.

It is interesting to note, with regard to the objective of successfully capturing the physical phenomena of the instability, that the use of a fuel injection model was necessary to obtain the rig results presented. It is possible to inject the fuel (reactant) at the boundary (inlet) of the simulation rather than at an interior cell. This is done by simply specifying the reactant fraction at the boundary. When this was done for the rig geometry just described, maintaining exactly the same flow rates and temperatures, the instability disappeared completely (this was not the case for the Pulse Jet simulation). This suggests that the coupling mechanism between heat release and pressure is predominantly related to variations of mixture ratio and convection
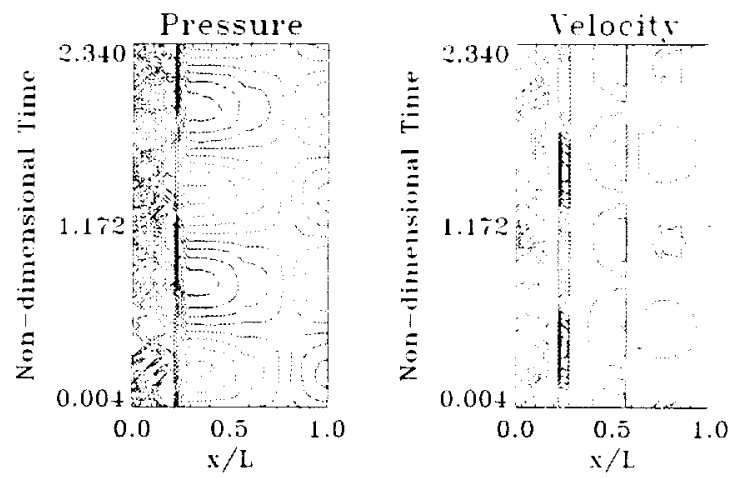

Figure 14. - Contours off non-dimensional pressure and velocity fluctuations for $\mathbf{2}$ cycles of the operating point 2 limit cycle.

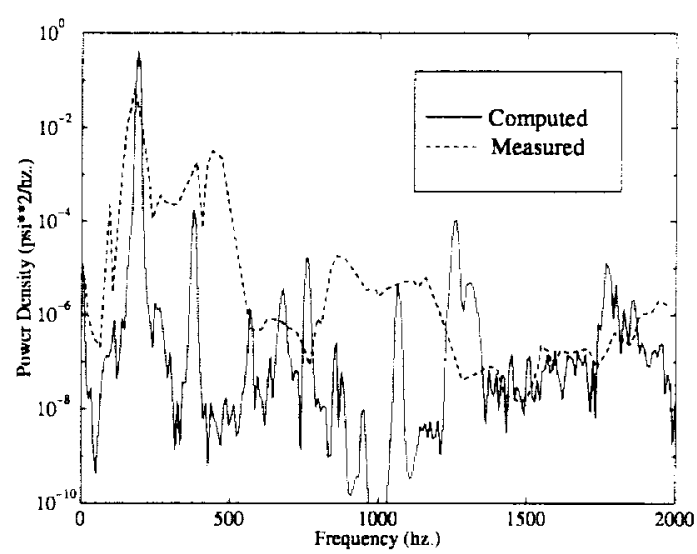

Figure 15.-Power spectral density distribution of pressure for $\mathrm{x}=\mathbf{4 2 . 1}$ inches during the operating point 2 limit cycle.

delays rather than to pressure induced variations in the reaction rate itself. The latter mechanism has been presented before in purely one-dimensional combustor simulations $^{3}$. The former mechanism is a more common explanation for combustors of the lean-premix type described here.

\section{$\underline{\text { Limitations }}$}

Restrictions regarding the applicability of the simulation method just described were mentioned in the introduction (premix combustors with longitudinal modes only). However, it is important to note several other important limitations.

\section{Diffusivity Distribution}

The particular rig simulation was, as mentioned, very sensitive to the prescribed distribution and magnitude of diffusivity. Recall that this distribution essentially determines the location of the reaction zone. Given the apparent dependence of the instabilities on convection time between the fuel injection point and the reaction 
zone, the sensitivity is not surprising. The distribution however, is completely heuristic at the time of this paper and as such, it must be concluded that it was 'tuned' in order to obtain results that were observed. In other words, had a slightly different distribution been chosen, no self-excited instability would have been observed. For example, if the flame position for Operating Point 1 is moved downstream just 0.3 in. (one grid point), the $292 \mathrm{hz}$. mode disappears and the $188 \mathrm{hz}$. mode dominates. If it is moved down $0.6 \mathrm{in}$. instabilities of any kind vanish. Furthermore, when the simulation was run at a third operating point, nearly identical to Operating Point 1 but with a higher inlet temperature, it produced essentially the same $292 \mathrm{hz}$. mode while experimentally no instability was detected. To some degree, this sensitivity may be a result of the particular rig simulated. Until a more physically based model can be developed for diffusivity however, it would seem that the use of this simulation as a reliable predictor of instability is premature. This is particularly true since, as stated, the use of diffusivity is itself a model of the effects of recirculating flow.

Another difficulty with the diffusivity distribution is that it cannot cross sectors. Diffusion terms in the governing equations can only be applied to interior numerical cells. Thus, since each sector is separated by a boundary, diffusion processes must begin and end within a sector.

\section{Flame Structure}

Related to the flame position or reaction zone, it should be kept in mind that, despite the geometric simplifications described herein, the actual flame structure in most lean, premix combustors is highly three dimensional. It does not closely approach the planar form assumed in this simulation. It is possible however, that an integrated average of the mutidimensional combustion/recirculation process would closely match that of the present simulation. This should be assessed using high fidelity numerical codes.

\section{Multiple area Changes}

Because the boundary condition routines associated with the sectored approach described here are highly iterative, their computational overhead is large. As such, the method becomes prohibitively time consuming if the number of area changes in a simulation is large.

\section{Conclusions}

The sectored-one-dimensional, numerical, reacting flow solver technique described in this paper reliably simulates the behavior of thermo-acoustic instabilities observed in premix combustors with complex crosssectional geometries. The fact that it is relatively simple (e.g. one-dimensional), yet reasonably accurate make it useful for characterization and testing of control strategies. Furthermore, modeling and implementation of control actuation, such as fuel flow perturbations, are straightforward in the framework of the simulation.

\section{References}

1. McManus, K.R., Poinsat, T., and Candel, S.M., "A Review of Active Control of Combustion Instabilities," Prog. Energy Combustion Science, Vol. 19, pp. 1-29, 1993.

2. Nalim, R.M., and Paxson, D.E., "A Numerical Investigation of Premixed Combustion in Wave Rotors," ASME Journal of Engineering for Gas Turbines and Power, Vol. 119, No. 3, 1997, pp. 668-675, also ASME Paper 96-GT-116, June 1996, also NASA TM-107242.

3. Quinn, D.D., and Paxson, D.E., "A Simplified Model for the Investigation of Acoustically Driven Combustion Instabilities," AIAA Paper 98-3764, July 1998.

4. Mawid, M.A., and Sekar, B. "A Numerical Study of Active Control of Combustion Driven Instabilities in Gas-Turbine Combustors," AIAA Paper 99-2778, June $1999^{\dagger}$.

5. Hirsch, C., Numerical Computation of Internal and External Flows, Wiley and Sons, 1990.

6. Paxson, D.E., "A General Numerical Model for Wave Rotor Analysis," NASA TM-105740, July 1992.

7. Paxson, D.E., "An Improved Numerical Model for Wave Rotor Design and Analysis," AIAA Paper 93-0482, January 1993, (also NASA TM-105915).

8. Thompson, P.A., Compressible Fluid Dynamics, Department of Mechanical Engineering Rensselaer Polytechnic Institute, 1988.

9. Press, William, H., et al, Numerical Recipes, Cambridge University Press, 1986.

10. Benade, Arthur H., Horns, Strings, and Harmony, Anchor Books, 1960.

11. Kentfield, J.A.C., Nonsteady One-Dimensional Internal Compressible Flows: Theory and Application, Oxford University Press, Oxford, England, UK, 1993.

12. Sterling, James, D., "Longitudinal Mode Combustion Instabilities in Air Breathing Engines," $\mathrm{PhD}$ Thesis, California Institute of Technology, Pasadena, California, 1987.

\footnotetext{
${ }^{\dagger}$ The numerical results presented in Ref. 4 were obtained using a 1-D code developed by D. Paxson at the NASA Glenn Research Center. This code is nearly identical to what is used in each sector of the present paper. It was provided to the Ref. 4 authors along with a User Manual and code description. Portions of the manual appear in Ref. 4. For completeness, these have also been included in the present paper.
} 


\section{Appendix: Difficulties of Q-1-D Formulations}

It would appear at first that a Quasi-One-Dimensional numerical approach would be practical for the combustor geometries described in this paper. Indeed, a reactive $Q-1-D$ code was developed by the author as an initial approach to modeling the experimental rig described herein and work continues on this approach. However, there are difficulties presented by this approach which, to date, the author has not been able to successfully resolve. All of the difficulties revolve around the implementation of the momentum source term $\mathrm{p} \frac{\mathrm{dA}}{\mathrm{dx}}$. The appropriate manner in which to evaluate this term numerically is somewhat ambiguous when the area gradients are large. Among other things, it seems to depend on the numerical integration scheme used. Furthermore, even if it is evaluated in a manner that produces a stable scheme, other difficulties may arise. These include, among others:

1. The need for many grid points in vicinities of area change.

2. Non-physical behavior such as local entropy loss (gains in total pressure) and/or unpredictable total pressure losses related to the area change.

3. Changing the acoustic properties of the system due to approximating abrupt area changes with something more gradual.
Additionally, Q-1-D formulations often result in flame locations precisely in vicinities of large area gradients. Since thermo-acoustic instabilities result from coupling between heat release and pressure perturbations, it may become unclear whether simulated instabilities are physically real or the result of numerics.

In any case, as mentioned in an earlier footnote, a Q-1$D$ simulation has not yet been implemented that successfully simulates the rig instabilities just described. They have however, been used to successfully simulate some Pulse Jet engines. 


\begin{tabular}{|c|c|c|c|}
\hline \multicolumn{3}{|c|}{ REPORT DOCUMENTATION PAGE } & $\begin{array}{l}\text { Form Approved } \\
\text { OMB No. 0704-0188 }\end{array}$ \\
\hline \multicolumn{4}{|c|}{ 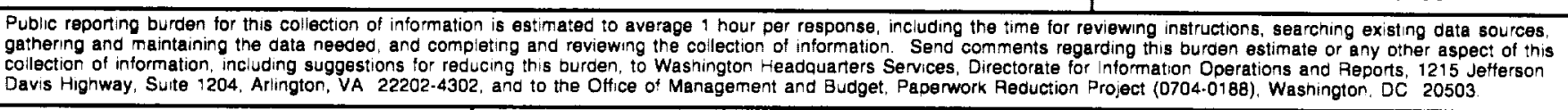 } \\
\hline 1. AGENCY USE ONLY (Leave blank) & $\begin{array}{l}\text { 2. REPORT DATE } \\
\text { December } 1999\end{array}$ & 3. REPORT TYP & $\begin{array}{l}\text { ND DATES COVERED } \\
\text { echnical Memorandum }\end{array}$ \\
\hline \multicolumn{3}{|c|}{$\begin{array}{l}\text { 4. TITLE AND SUBTITLE } \\
\text { A Sectored-One-Dimensional Model for Simulating Combustion Instabilities } \\
\text { in Premix Combustors }\end{array}$} & \multirow{2}{*}{$\begin{array}{l}\text { 5. FUNDING NUMBERS } \\
\text { WU-523-26-13-00 }\end{array}$} \\
\hline \multicolumn{3}{|l|}{$\begin{array}{l}\text { 6. AUTHOR(S) } \\
\text { Daniel E. Paxson }\end{array}$} & \\
\hline \multicolumn{3}{|c|}{$\begin{array}{l}\text { 7. PERFORMING OAGANIZATION NAME(S) AND ADDAESS(ES) } \\
\text { National Aeronautics and Space Administration } \\
\text { John H. Glenn Research Center at Lewis Field } \\
\text { Cleveland, Ohio } 44135-3191\end{array}$} & $\begin{array}{l}\text { 8. PERFORMING ORGANIZATION } \\
\text { REPORT NUMBER } \\
\text { E- } 12051\end{array}$ \\
\hline \multicolumn{3}{|c|}{ 9. SPONSORING/MONITORING AGENCY NAME(S) AND ADDRESS(ES) } & $\begin{array}{l}\text { 10. SPONSORING/MONITOAING } \\
\text { AGENCY REPORT NUMBER } \\
\\
\text { NASA TM-1999-209771 } \\
\text { AIAA-2000-0313 }\end{array}$ \\
\hline \multicolumn{4}{|l|}{ 11. SUPPLEMENTARY NOTES } \\
\hline
\end{tabular}

12a. DISTRIBUTIONAVAILABILITY STATEMENT

12b. DISTRIBUTION CODE

Unclassified - Unlimited

Subject Categories: 07 and 02

Distribution: Nonstandard

This publication is available from the NASA Center for AeroSpace Information, (301) 621-0390.

13. ABSTRACT (Maximum 200 words)

A one-dimensional, CFD based combustor simulation has been developed that exhibits self-excited, thermo-acoustic oscillations in premixed combustor geometries that typically have large, abrupt changes in cross sectional area. The combustor geometry is approximated by dividing it into a finite number of one-dimensional sectors. Within each sector, the equations of motion are integrated numerically, along with a species transport and a reaction equation. Across the sectors, mass and energy are conserved, and momentum loss is prescribed using appropriately compatible boundary conditions that account for the area change. The resulting simulation and associated boundary conditions essentially represent a one-dimensional, multi-block technique. Details of the simulation code are presented herein. Results are then shown comparing experimentally observed and simulated operation of a particular combustor rig that exhibited different instabilities at different operating points. It will be shown that the simulation closely matched the rig data in oscillation amplitudes, frequencies, and operating points at which the instabilities occurred. Finally, advantages and limitations of the simulation technique are discussed.

\begin{tabular}{|c|c|c|c|}
\hline \multirow{2}{*}{\multicolumn{3}{|c|}{$\begin{array}{l}\text { 14. SUBJECT TERMS } \\
\text { Combustion; Simulation; Computational fluid dynamics }\end{array}$}} & \multirow{3}{*}{\begin{tabular}{|c|} 
15. NUMBER OF PAGES \\
18 \\
16. PAICE CODE \\
$\mathrm{AO} 3$ \\
20. LIMITATION OF ABSTRACT
\end{tabular}} \\
\hline & & & \\
\hline $\begin{array}{l}\text { 17. SECURITY CLASSIFICATION } \\
\text { OF REPORT }\end{array}$ & $\begin{array}{l}\text { 18. SECURITY CLASSIFICATION } \\
\text { OF THIS PAGE }\end{array}$ & $\begin{array}{l}\text { 19. SECURITY CLASSIFICATION } \\
\text { OF ABSTRACT }\end{array}$ & \\
\hline Unclassified & Unclassified & Unclassified & \\
\hline
\end{tabular}

